Viewpoints and Letters to the Editor are published in Hort- comments on matters of concern to horticulturists. These are Science to provide members of the American Society for Hor- not statements of official Society policy nor do they necessarticultural Science an opportunity to share their experiences and ily reflect the views of a majority of the Society's members.

\title{
Standardizing Research Clones in Ornamental Horticulture
}

\author{
Edward McWilliams \\ Department of Horticultural Sciences, Texas A\&M University, College Station, TX 77843
}

\begin{abstract}
Plants are research tools and we should standardize our plants, including those used for in vitro propagation studies, as carefully as we standardize our statistical methodology and instrumentation. A paramount assumption in research is that experiments can be reproduced. When this principle is violated inadvertently (e.g., by researchers using different genetic material), we may have results that are nonreproducible or, at least, difficult to compare. Further effort may be wasted as researchers attempt to reconcile and interpret conflicting results. This is not a firm foundation on which to build the subdiscipline of floriculture/ornamental/environmental horticulture (FOEH). One could say that this is stating the obvious and suggesting that we reinvent the wheel. No claim is made that using known genetic material in research is original, merely that FOEH researchers often do not.
\end{abstract}

One of the many reasons molecular biology research has rapidly moved forward is that isolates (clones) are widely shared by researchers in that field. Similarly, research on growth chamber uniformity has long been facilitated by floriculturists using the same cultivar. Research ornamental horticulturists and floriculturists struggle with many minorul crops, and our problems are further confounded by use of undefined clones, particularly of woody ornamental and foliage species. In some' cases, this problem cannot be avoided, but through cooperation it may be. Using whatever clone is at hand is finewhen one's paper is the first on a species; however, as more information accumulates, research advantages are gained by using a standardized clone (Kester, 1983) as a research model.

In Texas, we have seen striking differences among the response of Coleus clones to salinity, Peperomia obtusifolia genotypes to low-light stress, and clones of Quercus virginiana to insect damage. It is sometimes assumed that such genetic variation does not occur or that physiological differences be-

Received for publication 26 Apr. 1989. The cost of publishing this paper was defrayed in part by the payment of page charges. Under postal regulations, this paper therefore must be hereby marked advertisement solely to indicate this fact. tween clones are minimal; however, the list of clonal differences are endless. In short, we do not need genotype as an uncontrolled variable in most of our research. Horticultural research has enough detractors as it is. Let us eliminate, where appropriate, this source of confusion and criticism.

In some cases, research groups have published results on a species when they were possibly working on different clones of the same species. As a specific example from the literature, Ficus benjamina is known to have many genotypes with different physiological characteristics. There is extensive literature (Agricola 1981 through 1989) on this species reporting that various kinds of stress result in leaf abscission. How many of the differences observed by various research groups are due to the experimental treatments imposed and how many are due to the innate characteristics of the specific clones used by the different researchers? Some of the differences in the literature dealing with this species and other ornamental might be reconcilable or interpretable if differences between clones were known. In the meantime, comparative studies of the various clones(?) of this species are needed to determine if the genetic material used by different research groups responds in the same way to identical stresses. In some cases, it may be easier and more dependable to determine if genetic differences occur in ornamental taxa by studying isozymes of the plants in question.

Clones are also important in woody plants and there is extensive ecological (HeslopHarrison, 1964), dendrological, and, to a lesser extent, horticultural literature on this subject. However, where "province" has been a key topic in forestry research because it impacts on growth, much less interest in the subject has been expressed by woody ornamentalists, who are primarily concerned with characteristics such as plant form and flower, fruit, and leaf color. In many cases, we do not know the specific geographical origin of the plants that we work with and the unstated assumption often is that such information is irrelevant. This assumption is often not true.

Commercial FOEH enterprises pursue an endless quest for new plants; it is the "allAmerican" marketing mechanism. Much
FOEH research helps to create and understand this new yearly crop of genetic variation. Biotechnology will accelerate both the production of new crops of cultivars of herbaceous and woody plants and the obsolescence of research information gained on old cultivars with different genetic traits. This process will no doubt happen in all agricultural crops, but because of the huge number of "croplets" studied by FOEH researchers, cultivar and species obsolescence will greatly impact the discipline. A pro-active strategy of dealing with increased numbers of clones is needed.

To reduce genotype- and ecotype-related variation in research on ornamental, ASHS reviewers should encourage FOEH researchers to standardize, or at least define, where possible and where appropriate, the clones, lines, or cultivars being worked with, as is already done to a great degree in most horticultural research. I recognize that clonal standardization is impossible in certain micropropagated plants exhibiting somaclonal variation.

For most asexually propagated plants, standardization of clones is possible but involves additional effort. However, we have found researchers to be cooperative in sending us propagules of their research plants. Since commercial cultivars change every few years in some crops, standardizing these cultivars is a more difficult, if not impossible, proposition. Production researchers usually will need to study the most commercially important cultivar(s) used by their industry.

A greater understanding of the genetic basis of commercially important clones may allow FOEH researchers to know when new cultivars need to be studied, when clone needs to be included as an experimental variable, and when only trivial genetic differences separate new clones from old ones. Where longer-term science is emphasized, as opposed to commercial production, selection of identified "research model" clones or cultivars needs to be standardized. This is a logical way to build a long-term, dependable FOEH data base. If FOEH is to advance as a science, we need the research equivalents of a floricultural Drosophila.

Standardizing research clones will not always be practical, because pure research logic is not always the best logic to follow to solve 
quickly and economically. The more time
and money that various research groups put into a given problem of a crop, i.e., leaf drop in Ficus benjamina, the more critical it becomes for results to be as repeatable and comparable as possible. When problems that are apparently simple turn out to be corn. plex, the use of standardized, genetically de- tined research clones may be the only way
to understand and solve these problems.

In summary, greater clone standardization and emphasis on model plants will initially create problems as to whose clone, ecotype, cultivar, or species will be studied. Obtaining and maintaining genetically defined or definable plant material will be expensive, but experimental repeatability is critical-it likely would save research time and money in the long run.

\section{Literature cited}

Heslop-Harrison, J. 1964. Forty years of genecology. Adv. Ecol. Res. 2:159-247.

Kester, D.E. 1983. The clone in horticulture. HortScience 18:831-837.

HortS Cience, Vol. 26(1),

JANUARY 1991 